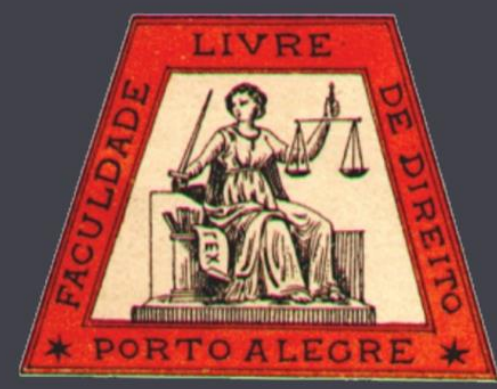

Da liberdade de expressão ao discurso de ódio: uma análise da adequação do entendimento jurisprudencial brasileiro à jurisprudência da corte interamericana de direitos humanos

From freedom of expression to hate speech: an analysis of the adjustment of the Brazilian case law to the case law of the InterAmerican Court of Human Rights

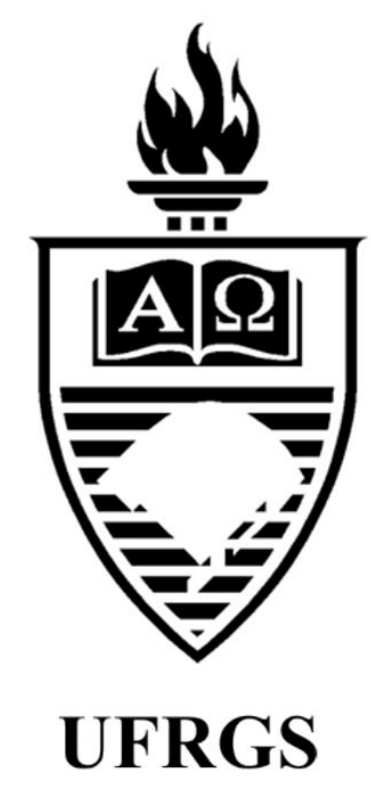

Ayla do Vale Alves

Universidade Estadual de Feira de Santana

Márcia Costa Misi

Universidade Estadual de Feira de Santana 


\title{
Da liberdade de expressão ao discurso de ódio: uma análise da adequação do entendimento jurisprudencial brasileiro à jurisprudência da corte interamericana de direitos humanos
}

\author{
From freedom of expression to hate speech: an analysis of the adjustment of the Brazilian case law to \\ the case law of the Inter-American Court of Human Rights
}

Ayla do Vale Alves*

Márcia Costa Misi* ${ }^{* *}$

\section{REFERÊNCIA}

ALVES, Ayla do Vale; MISI, Márcia Costa. Da liberdade de expressão ao discurso de ódio: uma análise da adequação do entendimento jurisprudencial brasileiro à jurisprudência da corte interamericana de direitos humanos. Revista da Faculdade de Direito da UFRGS, Porto Alegre, n. 35, vol. esp., p. 149-170, dez. 2016.

\section{RESUMO}

A partir do reconhecimento do compromisso firmado pelo Brasil de adequar suas decisões e seus entendimentos jurisprudenciais à jurisprudência da Corte Interamericana de Direitos Humanos, busca-se analisar, dentro do tema do direito à liberdade de expressão e, mais especificamente, do limite a essa liberdade quando diante de um discurso de ódio, se o Judiciário brasileiro tem cumprido com as obrigações assumidas pelo Estado de promover a referida adequação, vez que a falta desta interfere, diretamente, na facticidade das decisões da Corte em relação à Ordem Jurídica brasileira. Busca-se abordar as jurisprudências referentes ao direito à liberdade de expressão e, consequentemente, as possíveis restrições a ela, por se entender fundamental a existência desta liberdade para se possibilitar o debate racional característico de um governo democrático, vez que a partir do debate no qual é possível se expressar livremente é que poderá ser determinado o interesse comum capaz de legitimar a própria democracia.

\section{PALAVRAS-CHAVE}

Liberdade de expressão. Discurso de ódio. Sistema Interamericano de Direitos Humanos. Jurisprudência brasileira.

\begin{abstract}
From the recognition of the commitment made by Brazil to adjust its decisions and its case law according to the case law of the Inter-American Court of Human Rights, it is intended to analyze, within the theme of the right to freedom of speech and, more specifically, the restrictions applied to it when faced with hate speech, if the Brazilian Judicial System has been complying with the obligation assumed by the State to promote such adjustment, once the absence of it interferes directly in the factuality of the Court's decisions towards Brazilian legal order. It is intended to approach the case law concerning freedom of speech and, consequently, the possible restrictions to it, for the existence of such freedom is considered fundamental to allow the rational debate proper of a democratic government, since it is from the debate in which one can express herself/himself freely that will be possible to determine the commom interest capable of legitimizing democracy itself.
\end{abstract}

\section{KEYWORDS}

Freedom of Speech. Hate Speech. Inter-American System of Human Right. Brazilian case law.

\section{SUMÁRIO}

Introdução. 1. Liberdade de expressão. 2. Discurso de ódio. 3. Jurisprudência da corte interamericana de direitos. 4. Jurisprudência brasileira - o entendimento do STF. Conclusões. Referências.

\footnotetext{
* Graduada em Direito pela Universidade Estadual de Feira de Santana - UFES.

** Professora da Universidade Estadual de Feira de Santana - UFES. Possui graduação em Direito pela Universidade Federal da Bahia (1994) e mestrado em Relações Sociais pela Pontifícia Universidade Católica de São Paulo (1999).
} 


\section{INTRODUÇÃO}

A construção do saber depende da comunicação, do discurso, do debate entre diferentes opiniões, da troca de informações. Com a evolução das tecnologias, das mídias, da internet, expandiram-se também as possibilidades e os espaços de comunicação, que se tornaram mais inclusivos e acessíveis. Assim, a existência de diversos canais de exposição de ideias e opiniões, principalmente no mundo virtual da internet, acabou por potencializar e facilitar o exercício da comunicação, a troca de informações e ideias e o exercício da liberdade de expressão em si.

A necessidade de comunicação, de expressão das opiniões e ideologias é fundamental à vida e ao crescimento humano, vez que a partir do discurso e da troca se permite construir o saber e se desenvolver o raciocínio.

Entretanto, para além de momentos de crise política, nos quais se observa um significativo aumento do fluxo de opiniões socialmente relevantes, inclusive diametralmente divergentes, a ampliação dos espaços de discussão e debate, a facilitação do acesso, principalmente por meio da internet, a notícias e conteúdos mais variados instigou um crescimento notável na participação, cada vez mais inclusiva, de pessoas de todas as dimensões da sociedade, todos os lugares, todos os níveis de escolaridade, de renda, de conhecimento acadêmico, ampliando o debate para além dos chamados "intelectuais", incluindo toda e qualquer pessoa que tenha uma opinião e acesso, principalmente, ao ambiente virtual.

Essa ampliação dos canais de exposição e divulgação de opiniões, informações e notícias, apesar de socializar o direito à liberdade de expressão, apresenta situações que expõem riscos $\mathrm{e}$ novos conflitos àqueles que deles participam. Mesmo os demais, aqueles que escolhem ficar aparte dos debates e distantes das discussões podem acabar por serem atingidos colateralmente pelas consequências daquilo que extrapola a livre manifestação de pensamento de outrem.

Tais situações derivam de excessos, abusos neste direito de expressão e livre manifestação do pensamento. Tais abusos e excessos derivam, por sua vez, da intolerância, da discriminação, do preconceito, ou seja, do ódio.

Diante da preocupação com a forma com que se exerce o direito fundamental à liberdade de se expressar, quando esta vem ferir outro direito fundamental, como a dignidade da pessoa humana, torna-se necessário lançar um olhar mais atento ao discurso de ódio, buscando compreender sua dimensão, suas fontes, suas consequências, seu lugar e sua atuação dentro do conflito entre direitos fundamentais (como liberdade de expressão e a dignidade da pessoa humana), frequentemente incompatíveis quando há propagação de discurso odioso.

Não há, na legislação brasileira, tratamento específico para esta expressão de opiniões de conteúdo negativo e ofensivo, entretanto, tornase cada vez mais necessário contextualizar este conceito no ordenamento brasileiro, atribuindolhe definição e alcance. Tal tarefa, enquanto inexistente legislação específica, recai sobre a jurisprudência dos Tribunais Superiores, principalmente do Supremo Tribunal Federal (STF), que será justamente o parâmetro utilizado neste artigo para que se possa conhecer como o Judiciário brasileiro trata de tal tema.

Desta forma, são analisadas as decisões mais paradigmáticas e relevantes sobre o tema, e que são, por esta razão, as mais abordadas nas demais pesquisas que investigam este assunto. Pretende-se destacar trechos dos julgamentos que reflitam o posicionamento do Tribunal e, a partir deles, busca-se formar um entendimento geral do STF em relação à liberdade de expressão e aos limites impostos ao exercício deste direito quando, por exemplo, o conteúdo 
expresso se trata de discurso de ódio.

Em meio a tal pesquisa, por se tratar de assunto intimamente ligado aos direitos fundamentais e, em âmbito global, aos direitos humanos, compreende-se como fundamental considerar o entendimento da Corte Interamericana de Direitos Humanos (CIDH), órgão jurisdicional e contencioso do Sistema Interamericano de Direitos Humanos e à jurisdição do qual o Brasil se submeteu ao reconhecer esta competência jurisdicional da Corte, por meio do Decreto Legislativo $n^{\circ} 89 / 98$, em 03 de dezembro de 1998.

A Corte Interamericana de Direitos Humanos tem competência para emitir pareceres, comumente solicitados pelos Estados com fins de conhecerem a correta interpretação de dispositivos da Convenção Americana de Direitos Humanos (CADH). Ademais, estabelece jurisprudência relevante por meio das decisões dos casos que lhe são submetidos e que envolvem desrespeito a direitos humanos nos/pelos Estados membros. Esta jurisprudência deve ser seguida pelos países signatários por força e através do instrumento conhecido como controle de convencionalidade, conceito que será propriamente explorado mais a frente. Ademais, a própria Corte já afirmou, expressamente, que a adequação do direito interno dos países à $\mathrm{CADH}$ e à sua jurisprudência é ação obrigatória.

Diante disto, a presente pesquisa será construída com fins de analisar o tratamento dado a casos que envolvam discurso de ódio pelo Supremo Tribunal Federal brasileiro, de forma a se tentar delinear os contornos jurídicos atualmente empregados ao discurso de ódio, correlacionando, todo o tempo, o entendimento da Suprema Corte com as diretrizes estabelecidas pela jurisprudência da Corte Interamericana de Direitos Humanos sobre o mesmo tema. Isto porque se considera a necessidade de adequação e consonância entre o tratamento dado em ambas as esferas: nacional e internacional (regional), no âmbito do Sistema Interamericano de Direitos Humanos (SIDH).

\section{LIBERDADE DE EXPRESSÃO}

Os direitos fundamentais são direitos básicos, indispensáveis, inerentes à condição humana, através dos quais se busca assegurar a todas as pessoas uma existência digna. A liberdade de expressão se trata de uma ramificação do direito fundamental à liberdade, tendo este, como escopo, a garantia, na condição de valor essencial à dignidade da pessoa, da existência de um espaço sem ingerência de terceiros, particulares ou Estado, no qual se propicie a qualquer indivíduo a possibilidade de realização de seus próprios objetivos, sem dever obediência a outrem (FREITAS, CASTRO, 2013).

Inserida nos direitos de primeira geração, a liberdade de expressão é considerada direito negativo, no qual se define um dever de abstenção do Estado, de não interferência estatal na esfera particular do sujeito, de forma que não se conceda ao Poder Público espaço de atuação positiva no sentido de impedir ou coibir a manifestação de opiniões ou ideias por parte dos cidadãos (LUNA, SANTOS, 2014). Tem-se, portanto, que se trata de um direito fundamental dos indivíduos, abrangendo a liberdade de consciência, de crença, culto, de acesso à informação jornalística, científica, etc, estando intrinsecamente ligado à livre manifestação de pensamentos, ideias, opiniões, posicionamentos, seja de interesse público ou não, carregados de importância e valor social ou não, por meio de qualquer forma de comunicação, na esfera pública ou privada, não necessariamente condicionada à verdade (CABRAL, ASSUNÇÃO, 2012).

A proteção à liberdade de expressão é alicerçada em diversos valores, os quais justificam a existência deste direito como meio 
para a realização de um fim. Tais valores traduzem a liberdade de expressão, basicamente, nas seguintes vertentes: a) como uma forma de assegurar uma satisfação individual; b) como um meio de alcançar a verdade; c) como um método de garantir a participação de todos os membros da sociedade nas decisões sociais e políticas, sendo um instrumento possibilitador da participação social democrática; e d) como um mecanismo de manutenção da balança entre a estabilidade e a mudança da sociedade.

$\mathrm{O}$ direito à liberdade de se expressar sempre esteve presente na história constitucional do Brasil. Desde a Constituição Imperial de 1824, na qual a liberdade de expressão era tratada como direito não absoluto, havendo previsão de responsabilização do autor de abusos e vedação à censura (2012), passando por retrocessos nos períodos antidemocráticos, marcados por restrições de direitos e liberdades, censura e repressão, notadamente nas Cartas de 1937 e 1967, até o ressurgimento da democracia referendado pela chamada "Constituição Cidadã" de 1988. Tal liberdade sempre foi abarcada e defendida pelas constituições brasileiras, ainda que havendo variações na amplitude da sua proteção em decorrência das limitações impostas ao seu exercício em determinados períodos políticos antidemocráticos.

Os direitos fundamentais, numa visão histórica global, eram considerados absolutos e ilimitados até o final do século XVIII, quando se fundamentavam no Direito Natural de John Locke, cabendo ao Estado apenas a função de garantidor. (2012). Hoje, entretanto, perderam a característica de absolutos diante do caráter universal que lhes foi atribuído, pelo fato de se viver em um mundo plural e democrático, no qual é necessária, para a manutenção da paz e da harmonia universais, a compatibilização dos direitos entre si e destes com os interesses e necessidades dos cidadãos.

Diante disto, torna-se fundamental indagar sobre as reais possibilidades de limitação ao exercício destes direitos intrínsecos ao homem, dentre eles, conforme o foco da presente pesquisa, o da liberdade de expressão.

Considerando-se seu caráter universal, a limitação à liberdade de se expressar se torna possível e, por vezes, necessária, quando se leva em conta a pluralidade da sociedade e os eventuais conflitos que o exercício deste direito trará quando prejudicar a existência de outros valores, como o da dignidade da pessoa humana e da igualdade.

Por isto, pode-se apontar as limitações dogmáticas impostas pelo próprio ordenamento jurídico como fronteiras a serem respeitadas quando exercida a livre manifestação do pensamento. Isto porque, dentro de um ordenamento, é necessário que os princípios, normas, valores e liberdades convivam em harmonia com outros preceitos constitucionais, de forma que não haja discrepâncias ou contradições axiológicas dentro daquela unidade sistêmica.

Da mesma forma, é elemento limitador das liberdades o dever de não incorrer em condutas ilícitas, previamente estabelecidas em legislação infraconstitucional, considerando-se que a lei, por ser fruto da soberania popular exercida indiretamente, teria legitimidade para oferecer tal restrição, alicerçada no princípio da legalidade. Cita-se aqui, por exemplo, o crime de calúnia, previsto no art. 138 do Código Penal e o crime de racismo disposto no art. 20, caput, da lei 7.716/89. (FREITAS, CASTRO, 2013).

$\mathrm{O}$ que resta indagar, portanto, é a possibilidade de restrição da liberdade de expressão quando a lei for silente. Caberia invocar o princípio da dignidade da pessoa humana, por exemplo, para opor limites ao exercício deste direito? E quando este próprio princípio estiver sendo violado por conta da fruição desta liberdade? Tais questionamentos são fundamentais quando o abuso e/ou o excesso 
na livre manifestação de um pensamento transforam tal liberdade em discurso de ódio.

Resumidamente, antecipando-se o que será a seguir discorrido, entende-se, no contexto do direito brasileiro, que a resposta para as perguntas do parágrafo anterior é "sim”, apesar de se entender ser necessária uma avaliação caso a caso para que não se corra o risco de ver configurada a prática de censura, incompatível com o Estado democrático.

Esta análise individualizada das situações é fundamental para que, utilizando-se o mecanismo da ponderação e o princípio da proporcionalidade, se verifique, em cada quadro específico, se o abuso à manifestação do pensamento ultrapassou a fronteira dentro da qual a liberdade de expressão é protegida. Tal excesso, vindo a discriminar, segregar, inferiorizar ou humilhar indivíduos ou grupos, inclusive incitando a violência contra estes, configura discurso de ódio, se tornando, portanto, limitador do exercício de tal liberdade.

\section{DISCURSO DE ÓDIO}

O discurso de ódio, por um lado, considerando que se trata da exteriorização de um pensamento, se relaciona intimamente com a liberdade de expressão. Por outro lado, ao promover, implícita ou explicitamente, a discriminação, inferiorização, intolerância, possivelmente ferindo a dignidade de um outro indivíduo ou grupo, colocando, portanto, em conflito direitos fundamentais de uma mesma hierarquia, não parece merecer proteção tal qual a conferida à legítima manifestação livre do pensamento, na qual o conteúdo expresso não é incitador de ódio e violência.

Esta contradição torna difícil a compreensão do próprio conceito do discurso de ódio, sua amplitude, a delimitação dos seus contornos para que se possa identificar o que, no seu conteúdo, ultrapassa o limite do direito à liberdade de expressão. Da mesma forma dificulta a tarefa, principalmente da doutrina e jurisprudência brasileiras, de buscar uma solução jurídica eficaz, capaz de evitar, reprimir e rechaçar o discurso de ódio, sem que isso viole o direito ao discurso livre, nem prejudique as premissas do Estado Democrático de Direito (LUNA, SANTOS, 2014).

Considerando-se a doutrina sobre este tema, encontram-se definições para o discurso odioso com núcleos muitas vezes similares, havendo divergência apenas quanto a alguns elementos que são ou não considerados pelos pesquisadores como definidores e fundamentais de tal conceito.

Primeiramente, considera-se importante trazer algumas considerações sobre o ódio em si: o estado ou sentimento que, expresso em palavras, busca a negação do outro, acusando, julgando e condenando arbitrariamente aquele(s) que é(são) diferente(s), pela simples razão de sêlo. De acordo com GLUCKSMANN (2007, p. 231), "o ódio (...) camufla uma angústia, uma decepção, enfim, um ódio a si mesmo. Por não aceitar seu próprio reflexo no espelho, a reação é quebrá-lo".

$\mathrm{O}$ autor afirma ainda que aquele que tem ódio "só reconhece em si e a seu redor o contágio moral que ele mesmo propaga como uma lei única e universal" (2007, p. 231). Quem odeia prefere as facilidades da caricatura e do preconceito à lógica do raciocínio, pois no ódio não há espaço para o outro, não há diálogo capaz de gerar conhecimento e consenso, há apenas a necessidade furiosa de estabelecer no outro, distante de si, a fonte da própria indignidade.

Por isso que o ódio, quando manifesto, passa a gerar efeitos nocivos, atacando e ofendendo os direitos fundamentais de um indivíduo ou grupo de pessoas, ultrapassando o limite do direito à liberdade de expressão.

MEYER-PFLUG (2009) traz a definição de discurso de ódio como a manifestação de 
"ideias que incitem a discriminação racial, social ou religiosa em determinados grupos, na maioria das vezes, as minorias". Neste conceito, no qual a incitação à discriminação é o elemento nuclear fundamental, pode-se considerar haver uma enumeração limitada dos critérios discriminatórios configuradores do discurso de ódio, vez que não teriam sido levados em conta, por exemplo, a discriminação por gênero, orientação sexual, identidade, origem, condições físicas (deficiências), etc.

Somando-se à definição de Samantha Meyer-Pflug, SILVA e BOLZAN (2012) consideram dois elementos como configuradores do discurso de ódio: a discriminação e a externalidade. Afirma se tratar de uma manifestação segregacionista, como consequência do seu caráter discriminatório, e que apenas passa a existir e gerar seus efeitos quando é conhecida por outra pessoa, que não o próprio autor. A necessidade de ser externalizado para configurar discurso de ódio vem do fato de que, sendo apenas pensamento, o ódio não tem poder para causar dano à sua eventual vítima, sendo, inclusive, incabível a intervenção jurídica naquilo que se mantém na mente do seu autor, já que o pensar é livre a todos. (SCHAFER, LEIVAS, SANTOS, 2015).

Considera-se relevante, neste âmbito, observar a definição de discurso de ódio que leva em conta os objetivos sociais desta forma de expressão do pensamento que, ao desqualificar, humilhar e inferiorizar indivíduos e/ou grupos, o faz pelo fato das vítimas do discurso serem consideradas pelos autores deste como "diferentes". (FREITAS, CASTRO, 2013). O ódio é, portanto, externalizado com o objetivo de promover a exclusão social dos que não se encaixam nos padrões estabelecidos pelos autores do discurso como os únicos aceitáveis.

Diante disso já se pode perceber que o discurso de ódio comumente vitima as "minorias", grupos marginalizados, hostilizados e historicamente oprimidos; aqueles que não possuem as mesmas características do(s) autor(es) ou que não partilham das mesmas ideias; por isto, os "diferentes".

Assim, analisando uma definição que enfoca essa característica opressora, o discurso de ódio ainda pode ser definido como toda manifestação que diminua "ou ofenda os membros das minorias tradicionalmente discriminadas, que estão em inferioridade numérica ou em situação de subordinação econômica, política ou cultural". (LUNA, SANTOS, 2014).

Em outras palavras, é toda expressão de pensamento que vise propagar, incitar, promover, instigar e/ou justificar o racismo, o machismo/misoginia, a homofobia, a xenofobia, o fascismo, o antissemitismo, a intolerância religiosa, o ódio aos índios e demais populações tradicionais, a discriminação social entre classes, o preconceito em razão de deficiências físicas ou mentais e todas as demais formas de ódio baseadas na aversão ao diferente, àquilo que não se conhece nem se busca conhecer, tomando-se, de pronto, como o "inimigo" a ser combatido.

Tais definições do discurso de ódio, conjuntamente consideradas, levam à conclusão de que, nas palavras de CARCARÁ (2014, p. 62):

O discurso de ódio, como forma de manifestação de
pensamento, traz consigo o direito de externar uma
ideia e ao mesmo tempo incide sobre a esfera da
autonomia privada, posto dirigir-se a contaminar
determinado ambiente com uma ideia de fúria
contra um grupo vulnerável, propagando-a sem
possibilidade de diálogo, de liberdade de escolha,
do exercício livre da autonomia privada.

Ou seja, extrapolando os limites da liberdade de expressão, o discurso de ódio tornase um obstáculo ao exercício de outros direitos fundamentais daquele que o discurso vitima, cerceando o diálogo, a construção do conhecimento, impedindo a liberdade de outro(s). 
Entretanto, no campo das liberdades, dos direitos fundamentais e direitos humanos, a colisão entre dois valores igualmente relevantes é sempre situação bastante delicada e, por vezes, subjetiva. A necessidade de utilização, para solução do conflito, do princípio da proporcionalidade e da ponderação abre espaço para uma certa subjetividade, de forma que, a depender da carga de valores que possui cada um que analisa o caso, torna-se possível a existência de interpretações diversas que defendem a prevalência de vertentes diferentes, senão opostas.

As vertentes do discurso de ódio dependerão da visão que se tem sobre a amplitude e o alcance do direito à liberdade de expressão. No direito norte-americano, por exemplo, prevalece a visão do "mercado de ideias", segundo a qual o Estado deve se manter neutro, sem proibir a expressão de qualquer pensamento, ainda que considerado equivocado, ofensivo ou preconceituoso por alguém, pois, para a construção do conhecimento, todas as ideias e opiniões devem ser expostas e consideradas por todos. Trata-se de uma liberdade de expressão praticamente absoluta, cabendo a intervenção estatal apenas em caso de violência clara e iminente.

A outra vertente seria, por exemplo, a adotada pelo modelo alemão. Segundo o entendimento do Tribunal Constitucional Federal Alemão, diante de uma colisão entre a liberdade de expressão e a dignidade da pessoa humana, consequência comum do discurso externalizador de ódio, o Estado não deve apresentar um discurso neutro, mas sim buscar evitar a propagação do pensamento odioso, declarando, em muitos casos, a rendição da liberdade de expressão para que prevaleça a dignidade humana, valor hierarquicamente superior na ordem jurídica da Alemanha.

Diante da constatação da existência de diversos tratamentos doutrinários e jurídicos possíveis acerca da dimensão da liberdade de expressão e sua relação com o discurso de ódio, mostra-se, então, fundamental conhecer $o$ posicionamento da jurisprudência brasileira sobre este tema. Neste sentido, tratando-se de valores de igual hierarquia no ordenamento brasileiro, cabe indagar qual a solução fornecida pelo Supremo Tribunal Federal, mais importante órgão jurisdicional do país, quando, diante do discurso de ódio, são postas em conflito a liberdade de expressão e a dignidade da pessoa humana ou outros valores constitucionalmente protegidos.

Entretanto, antes mesmo de se buscar conhecer o entendimento do mais alto tribunal nacional, reputa-se necessário verificar ainda, qual a interpretação dada sobre o tema pela Corte Interamericana de Direitos Humanos (CIDH), órgão jurisdicional e autônomo criado no âmbito do Sistema Interamericano de Direitos Humanos (SIDH). Isto se faz em atenção aos instrumentos do Controle de Convencionalidade e do Controle de Supralegalidade - apesar de ainda controvertidos dentro do ordenamento brasileiro - pelos quais, resumidamente, é valorada e buscada, como mecanismo de solução de antinomias entre normas, a compatibilidade entre as regras internas e os tratados internacionais de direitos humanos ratificados pelo país e nele em vigor. Mais será abordado sobre o SIDH e sobre tais mecanismos em seguida.

\section{JURISPRUDÊNCIA DA CORTE INTERAMERICANA DE DIREITOS HUMANOS}

Conforme retro afirmado, o propósito do presente artigo é realizar uma análise da jurisprudência brasileira afeta ao tema do discurso de ódio, utilizando-se, como paradigma ou parâmetro, a jurisprudência da Corte Interamericana de Direitos Humanos sobre o mesmo tema. A pesquisa, tal como é proposta, 
visa aderir ao entendimento da CIDH sobre o papel do Poder Judiciário de cada país signatário na busca pela adequação entre normas da Convenção Americana de Direitos Humanos e jurisprudência da CIDH com as normas e decisões internas, considerando, ainda, a tendência, entre países integrantes do SIDH, de seguir este mesmo entendimento.

Para que se tornem claros os conceitos de Controle de Convencionalidade e de Controle de Supralegalidade, inicialmente, traz-se parte de uma decisão da Corte, na qual consta:

\begin{abstract}
A Corte está ciente de que os juízes e tribunais estão sujeitos ao império da lei e, portanto, são obrigados a aplicar as disposições vigentes no ordenamento jurídico. Mas quando um Estado ratifica um tratado internacional, como a Convenção Americana, seus juízes, como parte do aparelho do Estado, também estão sujeitos a ela, o que os obriga a garantir que os efeitos das disposições da Convenção não sejam prejudicados pela aplicação de leis contrárias a seu objeto e finalidade, que desde o início carecem de efeito jurídico. Em outras palavras, o Poder Judiciário deve exercer uma espécie de "controle de convencionalidade" entre as normas jurídicas nacionais aplicáveis aos casos concretos e na Convenção Americana sobre Direitos Humanos. Nessa tarefa, o Poder Judiciário deve levar em conta não só o tratado, mas também a interpretação dada pela Corte Interamericana, intérprete última da Convenção Americana. (CIDH: Caso Almonacid v. Chile, 2006)
\end{abstract}

$\mathrm{Ou}$ seja, a própria Corte internacional decidiu que todos os Estados sujeitos à sua jurisdição, como o Brasil, estão obrigados, por meio dos seus magistrados, a realizar o controle de convencionalidade, respeitando, inclusive, a jurisprudência da própria Corte, que tem caráter vinculante.

Diante disto se observa que os controles citados, no âmbito do SIDH, se referem a uma obrigação, segundo a decisão da Corte, de que os países submetidos à sua jurisdição realizem uma compatibilização vertical das leis, por meio da busca pela adequação das normas e decisões judiciais internas em relação às normas da
Convenção Americana sobre Direitos Humanos e à jurisprudência da CIDH. Em decisão proferida no julgamento do Recurso Extraordinário (RE) 466.343-SP, assim como do Habeas Corpus (HC) 87.585-TO, o STF seguiu a decisão deste Tribunal internacional e, procedendo à compatibilização de norma brasileira às normas da Convenção Americana, declarou a inconstitucionalidade do art. 5, II da Constituição da República Federativa do Brasil (CRFB/88), extinguindo a prisão do depositário infiel, vez que se tratava de instituto inexistente na $\mathrm{CADH}$.

Reforçando a determinação da Corte no sentido de ser cogente a realização, pelos juízes nacionais, do controle de convencionalidade, tem-se o voto do juiz brasileiro, componente do Tribunal Interamericano, Augusto Cançado Trindade, na decisão do caso Última Tentação de Cristo (Olmedo Bustos e Outros) v. Chile (2001):

A Convenção Americana, além de outros tratados
de direitos humanos, buscam (...) ter no direito
interno dos Estados Parte o efeito de aperfeiçoa-lo,
para maximizar a proteção dos direitos
consagrados, acarretando, neste propósito, sempre
que necessário, a revisão ou anulação de leis
nacionais (...) que não se conformem com seus
padrões de proteção.

Quanto à diferenciação entre o Controle de Convencionalidade e o de Supralegalidade, tratase de tema ainda mais controverso, por não ser amplamente discutido e não haver um consenso significativo na doutrina brasileira, além da falta de um posicionamento jurisprudencial consolidado acerca da aplicação destes mecanismos no judiciário nacional.

Da forma que ora se pretende explaná-los, pode-se diferenciar o controle de convencionalidade do controle de supralegalidade pelo fato daquele utilizar, como parâmetro para a compatibilização vertical das normas e decisões internas, os tratados sobre direitos humanos que foram aprovados de acordo com o procedimento especial previsto no art. 5, 
$\S 3^{\circ}$ da Constituição Federal (obtendo status, portanto, de Emenda Constitucional), enquanto este utiliza como parâmetro os demais tratados sobre direitos humanos, aprovados pelo rito comum (que, segundo entendimento do STF, internalizados ao direito brasileiro, recebem status de norma supralegal).

Apresentadas tais definições, passa-se à análise do entendimento da Corte acerca do tema da liberdade de expressão e dos seus limites, dentre eles, o discurso de ódio. A livre manifestação do pensamento é abordada na Convenção Americana sobre Direitos Humanos $(\mathrm{CADH})$, principalmente, em seu art. 13, que segue (1969):

Artigo 13 - Liberdade de pensamento e de expressão

1. Toda pessoa tem o direito à liberdade de pensamento e de expressão. Esse direito inclui a liberdade de procurar, receber e difundir informações e idéias de qualquer natureza, sem considerações de fronteiras, verbalmente ou por escrito, ou em forma impressa ou artística, ou por qualquer meio de sua escolha.

2. O exercício do direito previsto no inciso precedente não pode estar sujeito à censura prévia, mas a responsabilidades ulteriores, que devem ser expressamente previstas em lei e que se façam necessárias para assegurar:

a) o respeito dos direitos e da reputação das demais pessoas;

b) a proteção da segurança nacional, da ordem pública, ou da saúde ou da moral públicas.

3. Não se pode restringir o direito de expressão por vias e meios indiretos, tais como o abuso de controles oficiais ou particulares de papel de imprensa, de frequências radioelétricas ou de equipamentos e aparelhos usados na difusão de informação, nem por quaisquer outros meios destinados a obstar a comunicação e a circulação de idéias e opiniões.

4. A lei pode submeter os espetáculos públicos a censura prévia, com o objetivo exclusivo de regular o acesso a eles, para proteção moral da infância e da adolescência, sem prejuízo do disposto no inciso 2 . 5. A lei deve proibir toda propaganda a favor da guerra, bem como toda apologia ao ódio nacional, racial ou religioso que constitua incitamento à discriminação, à hostilidade, ao crime ou à violência.

\section{A Corte Interamericana de Direitos}

Humanos expõe a existência de duas dimensões da liberdade de expressão: uma dimensão individual e uma dimensão social.

Em sua dimensão individual, a liberdade de expressão implica que ninguém seja arbitrariamente privado ou restringido de manifestar suas opiniões e pensamentos, abordando, portanto, o direito individual de cada um a discursar livremente. Para isso, está incluso nesta dimensão o direito de um indivíduo utilizar qualquer meio para difundir, na escala que desejar, a informação ou pensamento que possui. Desta forma, percebe-se que a expressão e a difusão do pensamento estão, aqui, imbricadas, sendo indivisíveis. Com isto, uma ação no sentido de restringir as possibilidades de divulgação do conteúdo que se expressa representa, igualmente, um impedimento ao direito de se manifestar livremente.

Esta dimensão implica, por outro lado, um direito coletivo de receber as informações que os outros possuem, de cada indivíduo conhecer o pensamento dos demais; trata-se do direito coletivo de todos (e cada um) se manterem informados. (CIDH: Caso Ivcher Bronstein v. Perú, 2001).

Já a dimensão social da liberdade de expressão funciona como "um meio para o intercâmbio de ideias e informações e para a comunicação massiva entre os seres humanos" (CIDH: Parecer Consultivo 05/85, 1985), compreendendo o direito de cada um de expor suas opiniões e pontos de vista aos demais, assim como o direito de todos a buscar e conhecer as diversas opiniões e pensamentos alheios. A Corte entende que, para o cidadão comum, seu direito de conhecer a opinião alheia e as informações que possuem os demais é tão importante quanto o direito de difundir seus próprios pensamentos e espalhar as informações que possui.

Segundo o entendimento da Corte, para o respeito pleno à liberdade de expressão, ambas as dimensões devem ser possibilitadas 
garantidas simultaneamente, considerando-se que possuem igual importância.

Várias interpretações e entendimentos foram firmados no bojo de decisões de casos referentes ao direito ao livre discurso submetidos à jurisdição contenciosa da Corte. Na sua atuação, a Corte estabeleceu, por exemplo, que "deve-se distinguir entre as restrições que são aplicáveis quando o objeto da expressão se refira a um particular e, por outro lado, quando faça referência a uma pessoa pública" (CIDH: Caso Ricardo Canese v. Paraguai, 2004). De acordo com este entendimento, a pessoa pública, por exercer funções ou atividades de interesse público, se expõe, voluntariamente, a um escrutínio público mais exigente, já que suas atividades se inserem na esfera do debate público (2004).

A CIDH se manifestou, ainda, sobre a importância da liberdade de expressão na formação da opinião pública, nos debates políticos e eleitorais, na atividade jornalística e, principalmente, na consolidação democrática das sociedades, ao estabelecer que "[...] a liberdade de expressão é uma pedra angular na própria existência de uma sociedade democrática" (2004).

Entretanto, buscando-se, nesta pesquisa, abordar a relação do discurso de ódio diante do direito fundamental à livre manifestação do pensamento, pretende-se focar, a partir de agora, nos entendimentos da CIDH acerca das possibilidades de se restringir o exercício deste direito.

Inicialmente, é importante estabelecer que o exercício da livre manifestação do pensamento deve ser a regra, por ser direito fundamental e imprescindível na sociedade democrática. Contudo, por não ser valor absoluto, pode ocorrer, em situações específicas, analisadas caso a caso, e desde que preenchidos critérios determinados, sua restrição, tal como afirmam o art. 13 da CADH, em seus incisos 4 e 5, e o art.
30 da mesma. Conforme parecer da Corte:

[...] nos termos da Convenção, as restrições autorizadas à liberdade de expressão devem ser aquelas 'necessárias para assegurar' a obtenção de certos fins legítimos, ou seja, não basta que a restrição seja útil para a obtenção deste fim, isto é, que se possa alcançar através dela, mas deve ser necessária, ou seja, que não possa ser alcançada razoavelmente por outro meio menos restritivo a um direito protegido pela Convenção.

(CIDH: Parecer Consultivo 5/85)

Ou seja, para que se restrinja o exercício do livre discurso, deve haver uma justificativa baseada em objetivos coletivos que, pela sua relevância e importância, sejam preponderantes em relação à necessidade social de exercer o direito à liberdade de expressão, e que esta restrição se limite ao absolutamente necessário. Quaisquer impedimentos ao gozo desta liberdade devem estar orientados a satisfazer um interesse público imperativo; apenas assim se terá uma restrição legítima.

Como exemplo se observa a decisão do caso Claude Reyes e Outros v. Chile, no qual a CIDH decidiu que "o direito de acesso à informação sob o poder do Estado admite restrições" (2006). Para tanto, contudo, devem ser preenchidos requisitos específicos que legitimem a limitação à liberdade referida. Conforme a mesma decisão, as eventuais restrições:

[...] em primeiro lugar, devem estar previamente determinadas por lei como meio para assegurar que não fiquem ao arbítrio do poder público. Estas leis devem ser aprovadas 'por razões de interesse geral e com o propósito para o qual foram estabelecidas.

[...] Em segundo lugar, a restrição estabelecida por lei deve responder a um objetivo permitido pela Convenção Americana. A este respeito, o artigo 13.2 da Convenção permite que se realizem restrições necessárias para assegurar "o respeito aos direitos ou à reputação dos demais" ou "a proteção da segurança nacional, da ordem pública ou da saúde ou da moral públicas". Finalmente, as restrições que se imponham devem ser necessárias em uma sociedade democrática, o que depende de que estejam orientadas a satisfazer um interesse público imperativo. Entre várias opções para 
alcançar este objetivo, deve-se escolher aquela que restrinja em menor escala o direito protegido. Isto é, a restrição deve ser proporcional ao interesse que a justifica e deve ser destinada a alcançar esse objetivo legítimo, interferindo na menor escala possível no efetivo exercício do direito. (CIDH: Caso Claude Reyes e outros Vs. Chile, 2006)

Diante deste trecho, a Corte estabelece, com algum grau de objetividade, as possibilidades e respectivos critérios para se restringir o exercício da liberdade de expressão. Ciente deste entendimento, cabe voltar às definições encontradas acerca do discurso de ódio. Neste sentido, ao afirmar que o artigo 13.2 da CADH permite a restrição da livre manifestação do pensamento para assegurar o respeito aos direitos ou à reputação dos demais, considera-se que a Corte reputa como legítima a limitação da liberdade de expressão quando diante de um discurso que propaga a violência e a discriminação, ou seja, o ódio.

Tal conclusão deriva da definição de discurso de ódio como a manifestação de um pensamento preconceituoso e violento, que, na sua expressão, viola o direito de outro de expressar seu próprio pensamento - vez que no ódio não há espaço para diálogo-, assim como fere sua dignidade, sendo esta princípio fundamental constitucionalmente garantido.

Destarte, extrai-se da jurisprudência da Corte Interamericana de Direitos Humanos, à qual o Brasil deve obediência, que, diante da manifestação de um pensamento que provoque desrespeito ao direito ou reputação alheios - o que ocorre quando se profere um discurso de ódio -, cabe restringir essa manifestação. Isto porque surge, no caso, um contexto que justifica uma limitação reputada necessária dentro de uma sociedade democrática.

Por fim, para que seja possível mensurar, caso a caso, quando há desrespeito ao direito, à reputação de uma outra pessoa para que, comprovada a violação, seja possível impor uma restrição à manifestação do pensamento, traz-se trecho de outra decisão da Corte, na qual se demonstra a importância da ponderação para a solução de tais conflitos. Nesta decisão se analisa um conflito entre direitos: de um lado, o direito à livre expressão do pensamento e, de outro, o direito à honra. Para solucioná-lo são estabelecidos critérios para efetivação de um juízo de ponderação sobre os valores em conflito. Veja-se:

\begin{abstract}
Para realizar esta ponderação deve-se analisar i) o grau de afetação de um dos bens em jogo, determinando se a intensidade dessa afetação foi grave, mediana ou moderada; ii) a importância da satisfação do bem contrário, e iii) se a satisfação deste justifica a restrição do outro. Em alguns casos, a balança se inclinará para a liberdade de expressão e, em outros, à proteção de direito à honra. (CIDH: Caso Kimel v. Argentina, 2008)
\end{abstract}

Esclarecidos os entendimentos da $\mathrm{CIDH}$ sobre o tema da liberdade de expressão e suas possíveis restrições, principalmente diante do discurso de ódio, e expostos os mecanismos utilizados por este Tribunal para solucionar o conflito que surge quando o exercício do direito de pensar e se expressar livremente de um prejudica direitos, liberdades e a dignidade de outros, cabe agora, em atenção aos controles de convencionalidade e supralegalidade defendidos pela Corte, analisar a adequação do direito brasileiro a estes posicionamentos.

\section{JURISPRUDÊNCIA BRASILEIRA - O ENTENDIMENTO DO STF}

Como já exposto, no ordenamento brasileiro, levando em conta, principalmente, a Constituição da República Federativa do Brasil, há ampla proteção às liberdades e, dentre elas, à liberdade de expressão, por se tratar de direito basilar dentro de uma sociedade democrática. Contudo, a própria Constituição impõe limites a essa livre manifestação de pensamento, como a vedação ao anonimato, a possibilidade de responsabilização ulterior por abusos e a 
proibição de violação à honra de outrem. Há, igualmente, dispositivos da legislação infraconstitucional que acabam por restringir $o$ discurso livre, como pode se destacar a Lei $\mathrm{n}^{\circ}$ $7.716 / 89$, que tipifica como crime, em seu artigo 20 , práticas racistas e discriminatórias.

Desta forma, não resta dúvidas de que há previsão, no ordenamento pátrio, de limites e restrições ao exercício da liberdade de expressão. Contudo, apesar de se concluir, pelo já exposto, que o discurso de ódio se trata de um abuso ao exercício dessa liberdade, criando, portanto, um novo limite a ser a ela imposto, ainda não se encontra, no sistema jurídico brasileiro, legislação que o proíba em toda a sua dimensão.

Diante desta omissão legislativa, resta recorrer ao entendimento jurisprudencial sobre o tema. Analisa-se, portanto, decisões do STF, como órgão julgador máximo e defensor da Constituição brasileira, para que se possa investigar como o discurso de ódio, sendo limitador da livre manifestação de ideias, é tratado no ordenamento brasileiro.

Primeiramente, intenta-se fazer uma análise de decisões que abordam a liberdade de expressão de forma mais generalizada. Em seguida, serão pontuadas as decisões que falam das possibilidades de restrição ao discurso livre, neste âmbito também se referindo ao discurso de ódio. Será então analisada uma decisão marcante para o tema: a decisão do chamado Caso Ellwanger. Por fim, serão expostos os critérios utilizados pelo STF para solução dos conflitos formados entre direitos fundamentais quando ocorrem excessos negativos no exercício desta liberdade.

Para abordar, de forma genérica e rápida, o tratamento que concede o Supremo Tribunal Federal ao direito fundamental à livre manifestação do pensamento, englobando sua importância na evolução, consolidação e manutenção de uma sociedade democrática, trazse trecho da decisão do RE com Agravo $n^{\circ}$
891647/SP, na qual é dito:

As ideias, ninguém o desconhece, podem ser fecundas, libertadoras, transformadoras ou, até mesmo, subversivas, provocando mudanças, superando imobilismos e rompendo paradigmas até então estabelecidos nas formações sociais. É por isso que se impõe construir espaços de liberdade, e tudo compatíveis com o sentido democrático que anima nossas instituições políticas, jurídicas e sociais, para que o pensamento não seja reprimido e, o que se mostra fundamental, para que as ideias possam florescer, sem indevidas restrições, em um ambiente de plena tolerância, que, longe de sufocar opiniões divergentes, legitime a instauração do dissenso e viabilize, pelo conteúdo argumentativo dos discursos fundados em convicções divergentes, a concretização de um dos valores essenciais à configuração do Estado Democrático de direito: o respeito ao pluralismo político. A livre circulação de ideias, portanto, representa um signo inerente às formações democráticas que convivem com a diversidade, vale dizer, com pensamentos antagônicos que se contrapõem, em permanente movimento dialético, a padrões, convicções e opiniões que exprimem, em dado momento histórico-cultural, o mainstream, ou seja, a corrente dominante em determinada sociedade. (STF - RE com Ag 891647-SP, 2015).

Ou seja, a liberdade de expressão se trata de um valor democrático, indispensável no âmbito de uma sociedade diversa, plural e composta de opiniões e convicções divergentes. Desta forma, a livre circulação das ideias, dentro deste contexto de diversidade e pluralismo político, é condição sine qua non para que se possibilite o "movimento dialético" de opiniões e posicionamentos divergentes, o qual, possibilitando, inclusive, o dissenso, cria espaço para o desenvolvimento da tolerância.

A Corte Constitucional nacional compreende, no entanto, que a amplitude desta liberdade não pode ser absoluta nem ilimitada. $\mathrm{Na}$ continuação da decisão trazida anteriormente (2015) o Supremo afirma:

Em uma palavra: o direito de dissentir, que constitui irradiação das liberdades do pensamento, não obstante a sua extração eminentemente constitucional, deslegitima-se quando a sua exteriorização atingir, lesionando-o, valores e bens 
jurídicos postos sob a imediata tutela da ordem constitucional, como sucede com o direito de terceiros à incolumidade de seu patrimônio moral.

Reforça-se o caráter não só legal, como constitucional, do direito de dissentir, mas põe-se a ressalva de que este direito perde sua legitimidade quando lesiona outros valores tutelados constitucionalmente. Ou seja, em uma situação fática na qual, exercendo seu direito de expressar livremente suas opiniões, um sujeito externaliza um pensamento cujo conteúdo vai de encontro com a ideia expressa por outrem, ainda que o pensamento traduza um posicionamento minoritário ou considerado por muitos como inaceitável, tratar-se-á de manifestação legítima, protegida pela liberdade de expressão. Contudo, se o conteúdo da manifestação ofende o patrimônio moral de outrem, a dignidade, a igualdade, ou algum outro valor ou bem jurídico protegido pela ordem constitucional, tal discurso perderá sua legitimidade, vez que a liberdade de expressão não pode ser usada para respaldar intolerância, preconceito, violência ou discriminação.

O Tribunal expressa ainda o entendimento de que deve prevalecer a proteção aos direitos da personalidade e à dignidade da pessoa humana quando, diante de um excesso no exercício do direito, tais valores entrarem em conflito com o direito à livre expressão do pensamento. Baseiase, para tanto, nas limitações e determinações impostas pela própria Constituição Federal. Na mesma decisão acima citada (2015) consta:

[...] a Constituição brasileira (...) conferiu significado especial aos direitos da personalidade, consagrando o princípio da dignidade humana como postulado essencial da ordem constitucional, estabelecendo a inviolabilidade do direito à honra $\mathrm{e}$ à privacidade e fixando que a liberdade de expressão e de informação haveria de observar o disposto na Constituição, especialmente o estabelecido no art. $5^{\circ}, \mathrm{X}$. Portanto, tal como no direito alemão, afigura-se legítima a outorga de tutela judicial contra a violação dos direitos da personalidade, especialmente do direito à honra e à imagem, ameaçados pelo exercício abusivo da liberdade de expressão e de informação.

Ainda sobre os limites de legitimação do discurso livre, explica o Supremo que (2015):

A prerrogativa concernente à liberdade de manifestação do pensamento, por mais abrangente que deva ser o seu campo de incidência, não constitui meio que possa legitimar a veiculação de insultos ou de crimes contra a honra de terceiros, especialmente quando as expressões moralmente ofensivas manifestadas com evidente superação dos limites da crítica e da opinião jornalísticas transgridem valores tutelados pela própria ordem constitucional.

Partindo do mesmo princípio que justifica a limitação da liberdade de expressão quando o exercício desta fere outro valor protegido pela ordem jurídica brasileira, o STF ressalta que a Constituição não protege ou ampara opiniões, ideias, escritos ou palavras que, uma vez expressas, caracterizam hipótese de ilícito penal, como ocorre nos casos dos crimes contra a honra: injúria, calúnia e difamação. Logo, a liberdade de manifestação do pensamento encontra limite também no direito infraconstitucional, quando a exteriorização do pensamento configurar um ilícito. Tal limitação pode ocorrer também nos casos dos crimes resultantes de preconceito de raça ou de cor, dispostos na Lei 7.716/89.

Para se verificar, em caso concreto, os entendimentos do STF acerca dos limites da liberdade de expressão e as circunstâncias em que o crime de racismo pode restringir o exercício deste direito, passa-se ao estudo de um caso paradigmático neste assunto. Analisa-se, então, a decisão proferida em sede do Habeas Corpus $\mathrm{n}^{\mathrm{o}}$ 82.424/RS, em 17/09/2003, que tratava de ação penal por crime de discriminação racial, originada no Rio Grande do Sul, tendo como réu o sócio da Revisão Editora LTDA e autor de livros com conteúdo considerado antissemita, Siegfried Ellwanger (CABRAL, ASSUNÇÃO, 2013). 
Em seus livros era incitada a aversão e desqualificação do povo judeu, assim como se pregava sua segregação. Desta forma, foi posto o conflito entre a garantia constitucional da liberdade de expressão, demonstrada pela manifestação de um pensamento, ainda que discriminatório, e os princípios da dignidade da pessoa humana e da igualdade racial, apresentado pelo direito fundamental dos judeus, sejam estes componentes de uma raça ou uma religião, de terem uma existência digna e não serem inferiorizados por suas características definidoras.

Diante deste conflito, ministros do STF utilizaram os princípios da proporcionalidade e ponderação de interesses para solução do conflito entre direitos. O resultado desta ponderação foi a conclusão de que "a liberdade de expressão não pode servir de respaldo para manifestações preconceituosas, nem incitar a violência e intolerância contra grupos humanos" (LUNA, SANTOS, 2014, p. 246). Ou seja, conclui-se, no caso, que os princípios da dignidade da pessoa humana e da igualdade racial deveriam prevalecer diante da liberdade de expressão. Foi levada em conta, nesta decisão, a proteção à minoria vítima do discurso e o respeito a limites jurídicos e morais, impostos a esta liberdade, como restrições necessárias em uma sociedade plural e (teoricamente) democrática.

Prosseguindo-se com a análise do caso, percebe-se evidente a prática do discurso de ódio, já que ocorreu uma manifestação de pensamento voltada para discriminar, segregar, incitar o preconceito e a intolerância contra as vítimas do discurso: os judeus. Assim, constatado o conteúdo discriminatório dos livros de Ellwanger, a grande questão do Habeas Corpus foi, então, acerca da possibilidade de se classificar "judeu" como raça ou não, com o fim de enquadrar ou não o discurso do escritor dentro do crime de racismo, inafiançável e imprescritível no direito brasileiro.

Sobre isto, a decisão do Pretório Excelso, utilizando-se aqui as palavras de CARCARÁ (2014, p. 135), foi no sentido de considerar que "raça não é um conceito biológico, e sim histórico, político e social, sendo a liberdade de expressão passível de restrição quando do seu excesso na prática de atos atentatórios à dignidade humana, e especial às minorias". Ou seja, a raça não se restringe a aspectos físicos, mas se define pelos grupos humanos em razão, por exemplo, da cor da pele, religião, origem, etc. $\left(2014\right.$, p. 134). Diante disto, o $\mathrm{HC} \mathrm{n}^{\mathrm{o}}$ 82.424/RS foi denegado, sendo Ellwanger condenado a dois anos de reclusão pelo crime de racismo.

Seguindo adiante na análise de outras decisões do STF sobre o tema, pode-se observar que o Tribunal expõe maneiras de como deve ser resolvido o conflito entre valores constitucionais quando a manifestação do pensamento apresenta um conteúdo tão ofensivo ao direito de outrem que se torna ilegítima, portanto, desmerecedora da proteção constitucional.

Diante do que se observou, o Supremo entende que a solução para este conflito só pode ser encontrada na análise específica de caso a caso, considerando as peculiaridades e a importância de se proteger cada valor em cada situação, além do peso que cada direito e violação a direito terá naquela conjuntura. $\mathrm{O}$ juízo de ponderação e proporcionalidade deve ser realizado considerando todas as circunstâncias e especificidades do caso concreto, de forma que não há possibilidade de indicar uma solução genérica, que abarcasse todos os casos de abuso ao direito de liberdade de expressão. $\mathrm{Na}$ decisão do Recurso Extraordinário com Agravo já citada consta:

[...] que a ponderação entre o princípio que consagra a liberdade de informação, de um lado, e o postulado que assegura a intangibilidade do patrimônio moral das pessoas, de outro, supõe a análise do contexto fático e a reavaliação do 
conjunto probatório a ele concernente (...)

(STF: RE 891647-SP, 2015)

Em seguida, o ministro Celso de Mello afirma que a própria Constituição Federal de 1988 impõe parâmetros para o exercício da liberdade de expressão nas suas diversas dimensões, especificando, no caso, a liberdade de informação jornalística. Segue detalhando, o ministro, a função do Judiciário na solução dos conflitos que surgirem quando do desrespeito a estes parâmetros. Afirma:

[...] cabendo, ao Poder Judiciário, mediante ponderada avaliação das prerrogativas constitucionais em conflito (direito de informar, de opinar, de criticar, de um lado, e direitos da personalidade, de outro) definir, em cada situação ocorrente, uma vez configurado esse contexto de tensão dialética, a liberdade que deve prevalecer no caso concreto. (...) É tarefa do intérprete encontrar o ponto de equilíbrio entre princípios constitucionais em aparente conflito, porquanto em face do princípio da unidade constitucional, a Constituição não pode estar em conflito consigo mesma, não obstante a diversidade de normas e princípios que contém. (2015)

Assim, reforça-se o entendimento de que a ponderação deve ser realizada em cada caso, buscando equilibrar, de acordo com as circunstâncias da situação concreta, por meio do balanceamento entre os valores conflitantes, qual liberdade deverá, naquele caso individual, ser mais amplamente defendida.

Aprofundando o entendimento da Corte Constitucional, observa, nesta mesma decisão, que um dos mecanismos que, impondo um limite a livre expressão do pensamento, soluciona o conflito surgido, é a responsabilização ulterior daquele que se excede no exercício do seu direito de se expressar. Para expor seu posicionamento neste aspecto, o Tribunal traz o trecho de uma decisão do Juiz americano Oliver Wendell Holmes Jr., proferida em voto de 1919, no julgamento do caso Schenck v. United States, na qual tal magistrado afirma que:
[...] a questão em cada caso é saber se as palavras foram usadas em tais circunstâncias e são de tal natureza que envolvem perigo evidente e atual (clear and present danger) de se produzirem os males gravíssimos que o Congresso tem o direito de prevenir. É uma questão de proximidade e grau.

(Caso Schenck v. United States - 249 U.S. 47, 52, 1919)

A decisão do STF é complementada em seguida com as seguintes considerações:

O fato irrecusável neste tema, é um só: o abuso no exercício da liberdade de expressão não pode ser tolerado. Ao contrário, deve ser reprimido e neutralizado, sempre, porém, a posteriori, eis que a liberdade de opinião não autoriza nem legitima práticas que atinjam e vulnerem, mediante imputações ofensivas, o patrimônio moral das pessoas, cuja proteção encontra fundamento no próprio texto da Constituição da República (art. $5^{\circ}$, $\mathrm{X}, \mathrm{c} / \mathrm{c}$ o art. $\left.220, \S 1^{\circ}\right)$.

(STF: RE 891647-SP, 2015)

Diante do exposto, cabe enfocar o conteúdo dos dispositivos constitucionais referidos no trecho supra: o art. $5^{\circ}$, inciso $\mathrm{X}$ e art. $220, \S 1^{\circ}$ da $\mathrm{CRFB} / 88$.

Art. $5^{\circ}$ Todos são iguais perante a lei, sem distinção de qualquer natureza, garantindo-se aos brasileiros e aos estrangeiros residentes no País a inviolabilidade do direito à vida, à liberdade, à igualdade, à segurança e à propriedade, nos termos seguintes:

(...)

IV - é livre a manifestação do pensamento, sendo vedado o anonimato;

$\mathrm{V}$ - é assegurado o direito de resposta, proporcional ao agravo, além da indenização por dano material, moral ou à imagem;

(...)

X - são invioláveis a intimidade, a vida privada, a honra e a imagem das pessoas, assegurado o direito a indenização pelo dano material ou moral decorrente de sua violação;

(...)

XIII - é livre o exercício de qualquer trabalho, ofício ou profissão, atendidas as qualificações profissionais que a lei estabelecer;

XIV - é assegurado a todos o acesso à informação e resguardado o sigilo da fonte, quando necessário ao exercício profissional;

Art. 220. A manifestação do pensamento, a criação, a expressão e a informação, sob qualquer forma, 
processo ou veículo não sofrerão qualquer restrição, observado o disposto nesta Constituição.

$\S 1^{\circ}$ Nenhuma lei conterá dispositivo que possa constituir embaraço à plena liberdade de informação jornalística em qualquer veículo de comunicação social, observado o disposto no art. $5^{\circ}, \mathrm{IV}, \mathrm{V}, \mathrm{X}, \mathrm{XIII}$ e XIV.

Pelo que se vê, confirma-se o já discorrido nesta pesquisa acerca da existência de limitações à liberdade de expressão no próprio texto constitucional. A vedação ao anonimato, o direito de resposta e indenização por dano moral, material ou à imagem são limitadores desta liberdade e se traduzem também em valores constitucionalmente protegidos.

O direito de resposta e a indenização decorrentes da violação de valores como honra e intimidade são, ainda, meios de solução para os conflitos originados do abuso no exercício da manifestação de pensamento. Assim, o Supremo Tribunal Federal, seguindo a Carta constitucional, defende a responsabilização ulterior daquele que, expondo suas ideias ou opiniões, viola direitos constitucionais alheios. A decisão da Reclamação Constitucional 18776/RJ, de relatoria do Ministro Dias Toffoli, aponta o seguinte:

Lógica diretamente constitucional de calibração temporal ou cronológica na empírica incidência desses dois blocos de dispositivos constitucionais (o art. 220 e os mencionados incisos do art. $\left.5^{\circ}\right)$.Noutros termos, primeiramente, assegura-se o gozo dos sobredireitos de personalidade em que se traduz a livre e plena manifestação do pensamento, da criação e da informação. Somente depois é que se passa a cobrar do titular de tais situações jurídicas ativas um eventual desrespeito a direitos constitucionais alheios, ainda que também densificadores da personalidade humana. Determinação constitucional de momentânea paralisia à inviolabilidade de certas categorias de direitos subjetivos fundamentais, porquanto a cabeça do art. 220 da Constituição veda qualquer cerceio ou restrição à concreta manifestação do pensamento (vedado o anonimato), bem assim todo cerceio ou restrição que tenha por objeto a criação, a expressão e a informação, seja qual for a forma, o processo, ou o veículo de comunicação social. Com o que a Lei Fundamental do Brasil veicula o mais democrático e civilizado regime da livre e plena circulação das ideias e opiniões, assim como das notícias e informações, mas sem deixar de prescrever o direito de resposta e todo um regime de responsabilidades civis, penais e administrativas. Direito de resposta e responsabilidades que, mesmo atuando a posteriori, infletem sobre as causas para inibir abusos no desfrute da plenitude de liberdade de imprensa.

A decisão é complementada ressaltando, ainda, a importância da existência de proporcionalidade entre o dano material e moral sofrido pela vítima e a indenização cabível, informando que, para realizar este juízo de proporcionalidade cabe considerar o "âmbito interno da potencialidade da ofensa e da concreta situação do ofendido" (2014).

Desta forma se observa, genericamente, que o STF também aponta a ponderação entre direitos e valores constitucionais, realizada pontualmente e especificamente diante das circunstâncias e elementos de cada caso, como a forma de se buscar o equilíbrio entre os direitos e valores que se aparentam em conflito.

Ressalte-se que, tratando-se de valores subjetivos que podem representar necessidades humanas diversas, com intensidades variáveis diante de contextos diferentes, a ponderação entre estes valores realmente só pode ocorrer levando em conta os aspectos fáticos específicos de cada situação específica.

Observou-se, igualmente, que o Tribunal dá suporte à previsão constitucional de responsabilização, a posteriori, e do direito de resposta por conta de abusos cometidos no exercício da liberdade de expressão. Para que a responsabilização seja justa e legítima, deve haver um juízo de proporcionalidade entre o dano causado pelo excesso na manifestação do pensamento e a indenização efetivamente percebida pela vítima. Da mesma forma, a resposta deve ser em medida justa e suficiente, apenas com fins de desfazer o dano causado pelo discurso abusivo. Assim se busca garantir que a indenização e a resposta não se tornem fatores de 
contração e restrição da liberdade. Ou seja, devese buscar sempre o meio que traga menos prejuízo à liberdade de expressão, ainda quando este meio esteja sendo utilizado para compensar um abuso anteriormente cometido.

Conhecendo-se, genericamente, em referência ao tema da liberdade de expressão, seus limites e limitadores, tanto os entendimentos da jurisprudência brasileira, ora representadas pelas decisões do Supremo Tribunal Federal, quanto a jurisprudência da Corte Interamericana de Direitos Humanos, já se torna possível a análise de adequação da primeira em relação a esta última. Desta forma, na crença de já restarem apresentados os elementos para tanto, passa-se às considerações finais desta pesquisa.

\section{CONCLUSÃO}

A liberdade de expressão, como direito fundamental e basilar no Estado democrático de direito, deve ser garantida e protegida. Entretanto, não se trata de direito absoluto, podendo e devendo sofrer restrições em nome da ponderação com outros valores constitucionais igualmente importantes. Esta restrição deve ser realizada com cautela para que se limite o mínimo possível tal liberdade e não configure censura.

Os limites de proteção da liberdade de expressão serão ultrapassados quando o discurso proferido tiver, como base, o ódio, ocasião em que a manifestação do pensamento não mais merecerá o resguardo da ordem constitucional. O discurso de ódio se trata de manifestação ofensiva, que visa promover a segregação e a violência contra, geralmente, grupos minoritários, social, histórica, cultural e/ou economicamente discriminados. Na busca de uma sociedade democrática, onde todos devem ter voz e as vozes devem ter o mesmo valor e respeito, estes grupos marginalizados devem ser protegidos e a manifestação de ódio contra eles rechaçada.

A Corte Interamericana de Direitos Humanos se pronunciou sobre o tema, reconhecendo limites à liberdade de expressão e defendendo a ponderação entre bens e valores quando diante de conflitos entre direitos e princípios fundamentais. O juízo de ponderação e proporcionalidade sempre deve ser feito analisando as circunstâncias específicas de cada caso concreto, para que, considerando-as, seja possível equilibrar os valores em jogo e escolher, de forma justa, privilegiar um ou outro direito.

A posição do Brasil reflete um país plural e diverso, que ainda segue em busca da concretização da democracia na sua ordem social e, consequentemente, também na ordem jurídica. A jurisprudência do STF, concordando com entendimentos da CIDH nos aspectos em que ambas foram analisadas, defende a necessidade de se restringir o direito à livre manifestação do pensamento quando, do exercício abusivo deste, surge um discurso de ódio incompatível com a ordem democrática.

Assim, quando a liberdade de expressão for máscara para o discurso de ódio, diminuindo a voz e visibilidade das minorias e distanciando a possibilidade de surgimento de uma sociedade igualitária e tolerante, o exercício desta liberdade se torna ofensa ao próprio sentido democrático da Constituição, devendo, portanto, ser restringido, considerando-se os parâmetros legais e jurisprudenciais citados

Com o propósito de analisar o fenômeno da violência psicológica contra meninas, praticada no ambiente familiar, tem o presente artigo a intenção de realizar uma análise de discurso de uma decisão judicial proferida pela Vara Especializada de Violência Doméstica e Familiar contra a Mulher de São Luís, Maranhão.

Trata-se de uma decisão que, para a sua construção discursiva, se situou num ponto de 
interseção entre a Lei Maria da Penha e o Estatuto da Criança e do Adolescente para, acolhendo uma correlação entre ambos os sistemas normativos, dar primazia ao maior interesse da criança, nisto considerando a importância do vínculo afetivo com o pai para o seu desenvolvimento psíquico.

Em seu teor, a referida decisão, mais tarde confirmada em sentença de MPU da infante, ressignificou os aspectos punitivos restritivos da lei, para determinar que os sujeitos envolvidos em uma situação de violência doméstica do tipo violência psicológica, pai e filha, se submetessem a tratamento psicológico familiar pelo prazo de um ano, para tanto levando em conta, sobremaneira, a vontade da criança de reconstruir uma boa convivência com o pai (COMARCA DE SÃO LUÍS DO MARANHÃO, 2016).

Para efeito de atender aos propósitos deste trabalho, qual seja o de analisar a prática discursiva adotada pelo Poder Judiciário, investiga-se de que forma esta pode ser capaz de construir novos saberes no que tange ao tratamento do fenômeno da violência contra a mulher. 


\section{REFERÊNCIAS}

BRASIL. Supremo Tribunal Federal. Recurso Extraordinário com Agravo $n^{o}$ 891647-SP. Recorrente Paulo Henrique Dos Santos Amorim, Recorrido Merval Soares Pereira Filho, Relator Min. Celso de Mello. J. 02 set. 2015.

BRASIL. Supremo Tribunal Federal. Reclamação Constitucional $n^{\circ} 18776-R J$. Reclamante Porta dos Fundos Produtora e Distribuidora Audiovisual S.A, Reclamada Juíza Coordenadora da Fiscalização da Propaganda Eleitoral do Tribunal Regional Eleitoral do Rio de Janeiro, Relator Min. Dias Toffoli. J. 03 out. 2014.

BRASIL. Supremo Tribunal Federal. Habeas Corpus $n^{\circ}$ 82.424-RS. Paciente Siegfried Ellwanger, Impetrantes Werner Cantalício João Becker e outra, Coator Superior Tribunal de Justiça. Relator Min. Moreira Alves. J. 17 set. 2003.

CABRAL, Hildeliza Lacerda Tinoco Boechat; ASSUNÇÃO, Caroline Oliveira de. HATE SPEECH: o Direito Fundamental à Liberdade de Expressão e seus Limites. Revista Doutrinas Jurídicas, Rio de Janeiro, 2013.

CARCARÁ, Thiago Anastácio. Discurso do ódio no Brasil: Elementos de ódio na sociedade e sua compreensão jurídica. Rio de Janeiro: Lumen Juris, 2014.

CIDH. Corte Interamericana de Direitos Humanos. Caso Almonacid v. Chile, 2006.

CIDH. Corte Interamericana de Direitos Humanos. Caso Claude Reyes e outros Vs. Chile, 2006.

CIDH. Corte Interamericana de Direitos Humanos. Caso Ivcher Bronstein v. Peru, 2001.

CIDH. Corte Interamericana de Direitos Humanos. Caso Kimel v. Argentina, 2008.

CIDH. Corte Interamericana de Direitos Humanos. Caso Ricardo Canese v. Paraguai, 2004.

CIDH. Corte Interamericana de Direitos Humanos. Caso Última Tentação de Cristo (Olmedo Bustos e Outros) v. Chile, 2001.

CIDH. Corte Interamericana de Direitos Humanos: Parecer Consultivo 5/85, 1985.

FREITAS, Riva Sobrado de; CASTRO, Matheus Felipe de. Liberdade de Expressão e Discurso de ódio: um exame sobre as possíveis limitações à liberdade de expressão. Revista Sequência, n. 66. Florianópolis, 2013.

GLUCKSMANN, André. O discurso do ódio. Rio de Janeiro: DIFEL, 2007.

LUNA, Nevita Maria Pessoa de Aquino Franca; SANTOS, Gustavo Ferreira. Liberdade de expressão e discurso de ódio. Revista Direito e Liberdade. Vol. 16. N. 03. Rio Grande do Norte: ESMARN, 2014.

MEYER-PFLUG, Samantha Ribeiro. Liberdade de Expressão e Discurso de Ódio. São Paulo: Revista dos Tribunais, 2009. 
ORGANIZAÇÃO DOS ESTADOS AMERICANOS - OEA. Convenção americana sobre os direitos humanos: pacto de San José da Costa Rica: assinada na conferência especializada interamericana sobre direitos humanos. San José, Costa Rica, 7 a 22 de novembro de 1969. Washington: OEA, 1970.

SCHÄFER, Gilberto; LEIVAS, Paulo Gilberto Cogo; SANTOS, Rodrigo Hamilton dos. Discurso de ódio: Da abordagem conceitual ao discurso parlamentar. Revista de Informação Legislativa, n. 207. Brasília, 2015.

SILVA, Rosane Leal da; BOLZAN, Luiza Quadros da Silveira. Discurso de ódio: Liberdade de expressão ou violação dos direitos humanos? Anais Simpósio de Ensino, Pesquisa e Extensão Unifra. Santa Maria: 2012.

TIBURI, Marcia. Como conversar com um fascista: Reflexões sobre o cotidiano autoritário brasileiro. Rio de Janeiro: Editora Record, 2015.

Recebido em: 05/12/2016

Aceito em: 30/01/2017 

à jurisprudência da corte interamericana de direitos humanos

Revista da Faculdade de Direito da UFRGS, Porto Alegre, n. 35, p. 149-170, vol. esp., dez. 2016.

ISSN: 0104-6594 Site http://seer.ufrgs.br/revfacdir 